\title{
Na parada de ônibus, à espera da tecnologia social*
}

\section{Awaiting for social technology at the bus stop}

Nathália Kneipp Sena'

* Recebido em: $24 / 11 / 2015$. Aprovado em: 01/06/2016.

1 Nathália Kneipp Sena é doutoranda em Gestão Ambiental no Centro de Desenvolvimento Sustentável da Universidade de Brasília (UnB). Mestre em Comunicação (Processos Comunicacionais nas Organizações) e pós-graduada em Educação a Distância, ambos os cursos pela Universidade Católica de Brasília (UCB). Formada em Jornalismo pela UnB.

\section{Resumo}

Considerações sobre o design de uma parada de ônibus são usadas neste trabalho como exemplo e elemento introdutório para se avaliar o conceito de tecnologia social (TS). Tal expressão é discutida e utilizada em países latino-americanos, como o Brasil, o México, a Argentina e o Uruguai. O texto inclui ponderações sobre quais identidades, discursos, imagens e valores podem estar associados à TS. Explicita-se como a TS e diferentes adjetivações da tecnologia ajudaram na promoção de ideário que clama por uma abordagem construtivista da ciência e tecnologia, diferenciada e compassada às constantes transformações e exigências de cada realidade local, com foco na qualidade de vida das pessoas. Ciência, tecnologia e sociedade são lembradas neste artigo como um movimento social propiciador de reflexões sobre o que distingue uma visão instrumentalista, determinista, substantivista ou construcionista no âmbito da sociologia da tecnologia.

Palavras-chave: Tecnologia social. Construtivismo. Paradas de ônibus. Sociologia da tecnologia.

\begin{abstract}
Considerations on the design of a bus stop are used in this work as an example and a preliminary element to think about the concept of social technology (ST). Such expression is discussed and practiced in Latin-American countries, such as Brazil, Mexico, Argentina and Uruguay. This paper adds discussions on which identities, discourses, values and images can be associated to ST. The article also approaches how ST and different attributes to the word technology helped to promote a set of ideas that claim for a constructivist view of Science \& Technology, different and encompassed with constant demands and transformations of local contexts, advocating for a better quality of life among human beings. Science, Technology and Society are mentioned in this text as a social movement that has brought up the questioning about what distinguishes an instrumental, deterministic, substantivist and constructivist view in terms of the sociology of technology.
\end{abstract}

Keywords: Social technology. Constructivism. Bus stop. Sociology of technology. 


\section{Introdução}

As paradas de ônibus - ou "abrigos de ônibus", no jargão dos arquitetos - de Brasília, e de outras cidades brasileiras, constituem uma referência adequada para se indagar a que veio o discurso da tecnologia social. Como uma tecnologia pode não ser social, se todas surgem em meio à sociedade? Que novidades acompanham esses textos, discursos, valores, imagens e identidades? Como interagimos com os frutos da tecnologia, das estruturas ou dos aparatos que nos cercam em nossa realidade quotidiana? Cogitamos ser construtivistas, ou seja, de alguma forma partícipes do processo de escolha, modelagem ou customização de tecnologias? Ou será que permanecemos meros expectadores de um mundo que nos serve de cenário para transitarmos sem participação, indiferentes ou mesmo desencantados?

Com o propósito de incitar o debate por meio desses questionamentos, realizou-se uma observação não participativa de alguns pontos de ônibus da cidade, prevalecendo os da área urbana e central de Brasília, além de outros três entre a ponte Juscelino Kubitscheck e a DF-140, trajeto que conduz ao Alphaville da capital federal, considerada área rural em expansão para urbana. Conjugadas a esse exemplo, encontram-se as indagações sobre os abrigos de ônibus, alguns artigos acadêmicos e da imprensa em mídia digital, de acesso livre via Internet, e que tratam do surgimento dessas edificações no cenário brasiliense e de outras cidades.

Acrescentaram-se às paradas de ônibus, escolhidas como acesso ao tema das tecnologias sociais, algumas das diversas adjetivações já aventadas para a palavra tecnologia, a qual permanece em processo de semiose, com a atribuição de vários adjetivos para qualificá-la. A observação desses atributos serve para ilustrar como se deu a construção de sentido inerente à discussão sobre o movimento Ciência, Tecnologia e Sociedade (CT\&S) e o ideário das tecnologias sociais com o horizonte de se buscar melhoria da qualidade de vida para as comunidades. No caso do Brasil, os usuários de ônibus, metrô e trens somam 85 milhões de pessoas, majoritariamente insatisfeitas com o transporte público que utilizam (CAITANO, 2011).

Ao narrar a maneira como a tecnologia permeia todas as dimensões de nossa vida e ao estabelecer a proposta de discussão sobre quem controla seu desenvolvimento, incluem-se no debate os autores Graeme Kirkpa- trick, Andrew Feenberg, Ralph Schroeder, David Hess, entre outros pesquisadores que se dedicaram a analisar e desenvolver teorias sobre a sociologia da tecnologia.

\section{Design e funcionalidade dos abrigos de ôni- bus}

A visão lateral do traçado da armação metálica das paradas de ônibus erguidas em 2008 no Distrito Federal tem formato semelhante a letra "y" (Figura 1). Tais estruturas foram feitas pela empresa europeia Cemusa, adquirida pela empresa francesa JCDecaux, em 2014, com design da globalização e, por isso mesmo, podem ser consideradas não lugares ${ }^{2}$. São modelos de grife e com eles foram introduzidos painéis de vidro no mobiliário de rua. A fabricante fornece esses itens a 171 cidades de 13 países. Nova York assinou contrato de um bilhão de dólares, segundo o Propmark (2005), para a aquisição de 3.300 paradas de ônibus, 330 bancas de jornais e 20 banheiros químicos, em 2005, com a mesma empresa que fornece a São Paulo, Rio de Janeiro, Belo Horizonte, Salvador, Manaus e Brasília, significativa parcela de seu mobiliário urbano.

Esses abrigos de ônibus, presentes em várias cidades brasileiras - e os de Brasília em particular - são modelos assinados pelo arquiteto Nicholas Grimshaw, que começaram a ser comprados e instalados em 2008. As estruturas diferem dos antigos pontos de ônibus brasilienses, feitos em alvenaria. A história da evolução dos abrigos de ônibus da cidade pode ser encontrada no estudo de Araújo (2010), com o detalhamento de todos os projetos, autores, plantas com medidas, dimensões e fotos. O pesquisador relata que na versão original do projeto de Grimshaw havia lugar destinado à inclusão da tabela com os horários dos ônibus. Porém, essa funcionalidade, indispensável em muitos países desenvolvidos, foi descartada em Brasília.

2 Termo cunhado por Marc Augé em seu livro Não lugares, de 1995, ao se referir a lugares transitórios e sem significado. 


\section{Figura 1 - Parada de ônibus na Esplanada dos Ministérios em Brasília e, ao lado, o traçado minimalista da estrutura}

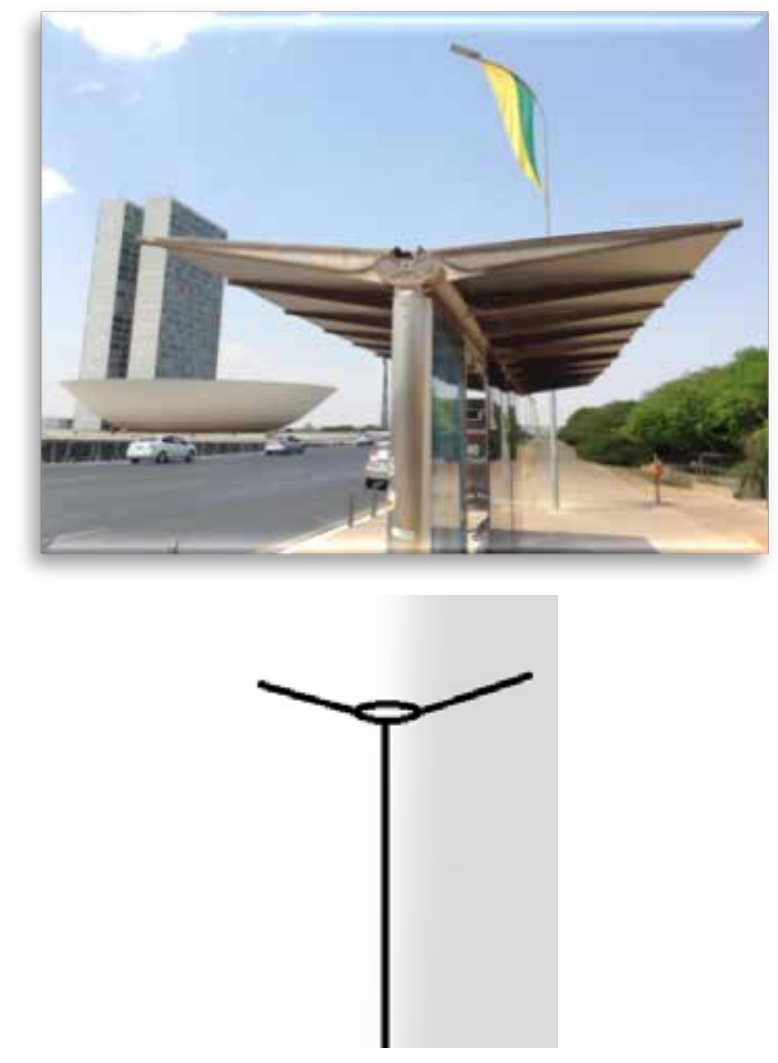

Fonte: Elaboração própria.

O signo evocado pela conformação dessas paradas, em um exercício de semiose - "todo signo interpreta outro signo" (ECO, 2004); ou de "esquizofrenia" via simbolização ("facilidade para colar arbitrariamente um significado em um objeto qualquer") (BAITELLO JUNIOR, 1997) - , lembra uma montagem minimalista do Cristo crucificado; um gerador de energia eólica; ou, se buscar-se investigar em uma tabela de sinais para a representação dualista ocidental, o garfo. Tais abstrações aparecem "ilustradas" com as imagens da figura 1. Em relação ao garfo, em formato de "Y": “[...] na Idade Média, era o símbolo da trindade. Pitágoras já o considerava como representação esquemática do curso da vida: a princípio, o caminho reto que a certo ponto se divide numa estrada 'boa' ou 'ruim'. Aberto para cima é o símbolo da alma que espera". (FRUTIGER, 1999, p. 53).

Há décadas o traçado que surge da prancheta de arquitetos pode alçar diversos voos simbólicos e estéticos, diferentes interpretações e representações que são produto da criatividade e de cognições desses profissionais, até chegar à escala de uso do protótipo construído e chumbado no chão. Por parte dos usuários de ônibus, a espera que se mantém é aquela da funcionalidade e ergonomia promotoras de qualidade de vida, a metáfora da estrada boa, uma tecnologia socialmente benquista. No propósito de constituir um abrigo temporário para transeuntes que usam o transporte público, tais estruturas pouco protegem as pessoas da chuva, do vento, da poeira e do sol, enquanto locais destinados à espera, que pode ser de alguns minutos ou horas, conforme o destino do passageiro. Cita-se, ainda, a questão do quantitativo de usuários, que cresce, exponencialmente, a cada ano.

Algumas paradas possuem uma aba menos abrangente, isto é, com dimensão reduzida. A estrutura de ferro é condutora de calor, conforme seu posicionamento em relação ao nascimento e pôr do sol. Se o sol incidir frontalmente e alcançar os usuários, isso pode equivaler a um calor tão acentuado que, pelo desconforto, as pessoas optam por permanecer fora do abrigo. O vidro foi motivo de reclamação em São Paulo, por criar ou acentuar uma sensação de abafamento (ROLNIK, 2013), como uma estufa, o que, supostamente, não deve ocorrer nos países de clima temperado que recebem os mesmos produtos. Rolnik (2013) advoga por maior conforto aos usuários de abrigos de ônibus e comenta que, em muitas ruas de São Paulo, o ponto ainda se limita a um toco ou estaca de ferro cravada no chão. Embora muitos neguem, com argumentos científicos, que as estruturas metálicas possam atrair descargas elétricas, há o risco e o receio de que isso ocorra. O Brasil é campeão mundial na incidência de raios - 50 milhões ao ano, ceifando centenas de vidas, anualmente, e deixando outros milhares feridos (EMPRESA BRASILEIRA DE COMUNICAÇÃO, 2014). Daniel Paz (2004, p. 1) expõe sua crítica ao uso dessas estruturas em Salvador: "além do fato de o arrojado ser um contrassenso funcional, os modelos mais belos são justamente os que, no uso cotidiano, registram as cenas mais aberrantes", comenta.

Em Brasília, entre a ponte Juscelino Kubitscheck e a DF-140, encontramos três funcionalidades distintas ou adicionais para os abrigos. A primeira foi a de um morador de rua que se instalou na parada, transformando-a em sua casa. Transcorridos alguns dias, somaram-se a ele outros dois moradores. O ponto foi superlotado com várias doações, de mobiliário a alimentos e tudo e todos terminaram sendo retirados do local, após alguns meses de ocupação (figura 2). Na parada próxima ao balão da Escola de Administração Fazendária (ESAF), foi introduzida a possibilidade de uso do álcool gel para desinfetar 
as mãos (figura 3), com o patrocínio do Departamento de Estradas de Rodagem do Distrito Federal (DER/DF), sem haver a lata de lixo disponível ao lado das paradas de ônibus da Esplanada dos Ministérios, por exemplo. Nesse caso, o entulho fica espalhado ao redor do ponto de transporte coletivo.

Outros usos e situações dessas estruturas são preocupantes e prejudiciais a todos os usuários, como o de banheiro a céu aberto, ponto de venda de drogas, local de emboscada que facilita a ação de assaltantes, estupradores e homicidas. Brasília também presenciou o ápice do horror em uma parada de ônibus, quando o índio pataxó Galdino Jesus dos Santos, de 44 anos, foi assassinado. No dia 20 de abril de 1997. Ele foi queimado vivo por cinco rapazes da classe média, que atearam fogo em seu corpo, quando ele dormia em um desses abrigos na W3 Sul. Tais "disfuncionalidades" problematizam várias questões, como a da ausência de bebedouros e de banheiros públicos, a disseminação das drogas e a falta de segurança nesses locais. Em setembro de 2015, a parada próxima ao Condomínio Mônaco, na DF-140, também conhecida como Rodovia Diogo Machado, ganhou a estátua de Cristo no teto (figura 4), com várias interpretações plausíveis sobre o porquê desse feito, inclusive a de que alguns abrigos servem como local de pregação para religiosos itinerantes.

Figura 2 - Morador de rua usa o ponto de ônibus como casa na DF-140

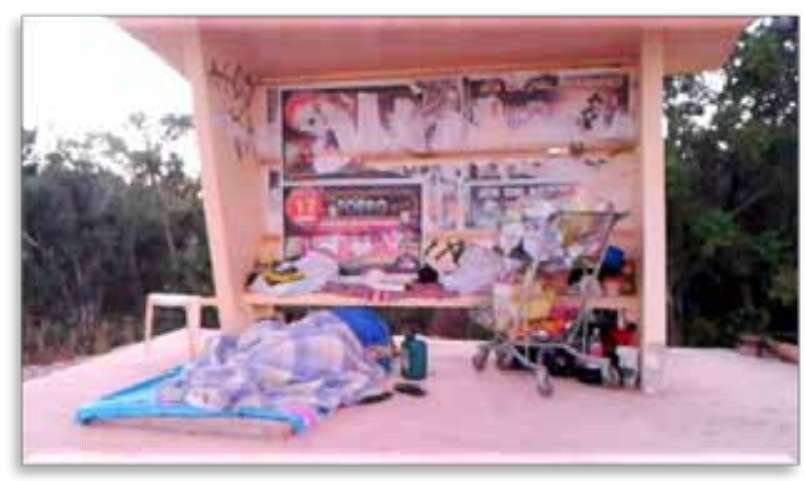

Fonte: Elaboração própria.
Figura 3 - Ao lado da parada próxima ao Jardim Botânico, é oferecido álcool gel para limpar as mãos.

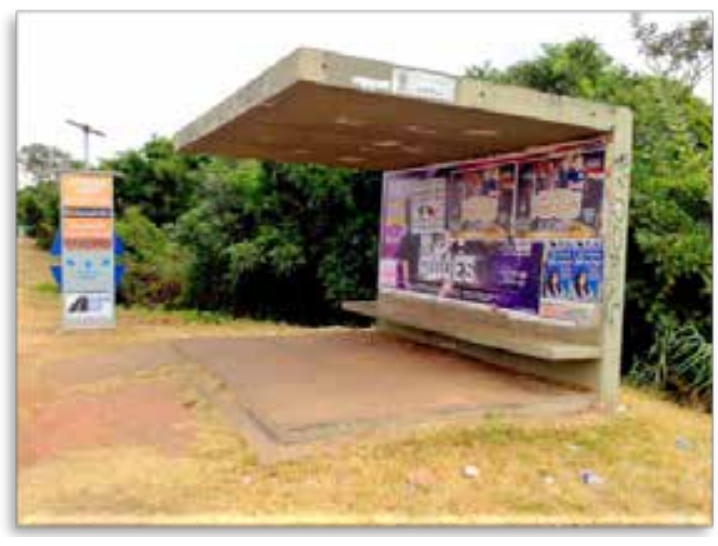

Fonte: Elaboração própria.

Figura 4 - Na DF-140, uma estátua de Cristo foi colocada sobre o ponto de ônibus

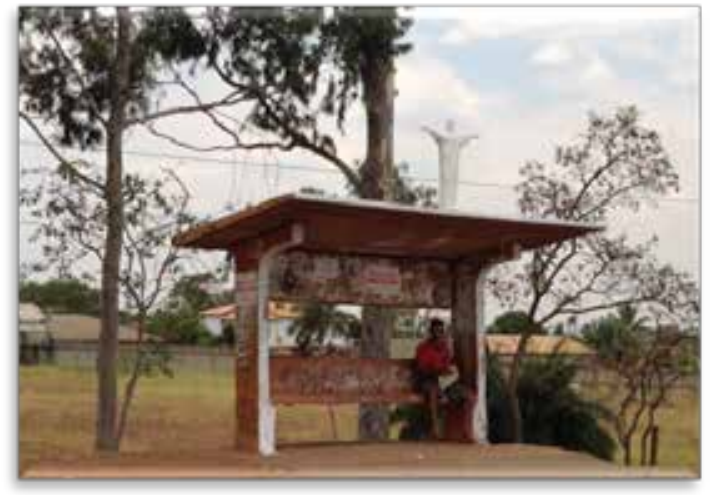

Fonte: Elaboração própria.

$\mathrm{Na}$ Internet, basta fazer a pesquisa no Google Imagens em "parada de ônibus", incluindo buscas subsequentes com a expressão traduzida para diversos idiomas, e olhar os resultados. Encontram-se muitas alternativas de design e materiais escolhidos para se construir uma parada de ônibus. Ao conhecer as diferentes concepções estéticas, o histórico dos projetos de Brasília permanece em estado de repetição de modelos com poucas alterações e redesenho do espaço circunvizinho desses pontos. Mundo afora há visuais e funcionalidades distintos nesse tipo de abrigo. A criatividade encontrada nos projetos revela que uma parada de ônibus pode assumir diversas formas e funções.

O exemplo da parada de ônibus serve como elemento de zoom in na realidade do tempo diário gasto na espera pelo transporte coletivo, seja na capital do país ou em outros estados. Tal amostra suscita a oportunidade de ponderar como as tecnologias sociais (TSs) podem incitar debates sobre a aplicação de um conhecimento que exerça um diferencial para a qualidade de vida das pessoas. 


\section{0 ideário da ciência, tecnologia e sociedade (C,T\&S)}

Para Kirkpatrick (2008), a tecnologia está envolvida na mediação e reconfiguração do poder social. O autor narra como os chimpanzés já utilizavam espetos, feitos de galhos, para colher frutas, chegando mesmo a guardá-los para utilização posterior. Pode-se localizar, nesse início de uso de um artefato para a mediação de uma necessidade básica - alcançar o alimento e ser capaz de alimentar-se -, a reconfiguração de poder. Exercitar poder é entendido pelo citado autor como a capacidade de conduzir os eventos na direção para a qual queremos que eles se encaminhem. A tecnologia surgiu, portanto, bem próxima de ser um elemento de empowerment das pessoas, na medida em que serve como intermediária entre as necessidades e os meios disponíveis para atendê-las.

$\mathrm{Na}$ história de como e com que meios de transporte as pessoas se deslocam, a bicicleta foi um dos artefatos narrados com passado construcionista ou construtivista, expressões usadas como sinônimas. Isso se deveu ao processo decisório daqueles que vivenciaram a maturação do invento, participando de suas diversas fases de construção e transformação. Havia a possibilidade de interagir e conduzir modificações nos diferentes designs aventados para o que se tornou a bicicleta de hoje. A roda bem grande garantia altura melhor para adequar os vestidos longos que as mulheres usavam no final do século XIX. A altura permitia que elas pedalassem, ainda que sem o conforto da calça comprida, opção mais bem-aceita para os homens, ante os costumes daquela época. Outras exigências, inclusive as de uso esportivo, fizeram com que o design e as funcionalidades fossem evoluindo até sair da fase de "flexibilidade interpretativa" em que os usuários opinam e sugerem adequações - e atingir o lock-in - formato final, satisfatório e atual - do artefato, aquele que se manteve (BIJKER; PINCH, 1997).

Ciência, tecnologia e sociedade pareciam poder evoluir como tríade bem-sucedida. Contudo, no século XIX, com o início da Revolução da Pesquisa (HESS, 1997), registraram-se novos encaminhamentos e perspectivas para as ciências. Momento de inserção da C\&T na inevitável bifurcação do garfo da trindade, mencionada na seção 2. As opções tecnológicas construídas na Alemanha e nos Estados Unidos conduziram ao que passou a ser conhecido como Big Science. Surgiram sistemas tecnológicos gigantescos, em laboratórios com milhares de cientistas, em sua maioria recrutados e com contratos de trabalho para fins bélicos. Essa é uma das razões por que Schroeder (2007) iguala a tecnologia ao desencanto pelo caminho escolhido, aquele da construção e emprego de armas de destruição em massa, entre outras tragédias atribuíveis às escolhas tecnológicas realizadas pela nossa espécie.

Para esse autor, tecnologia é sinônimo de "refinamento e manipulação". Schroeder postula "que o mundo e o conhecimento são separados, como o são os artefatos e o meio ambiente que eles moldam, o que faz com que seja a principal tarefa das ciências sociais analisar como os dois lados se entrosam." (SCHROEDER, 2007, p. 2). Considera o construcionismo uma ortodoxia entre os pesquisadores. Argumenta que, para se compreender a relação entre ciência, tecnologia e mudança social, é essencial discernir em que aspectos cruciais a ciência está separada da cultura e da sociedade. O carro, o telefone e a televisão constituem três exemplos citados pelo autor ao expor como a tecnologia torna-se cultura a partir do momento em que é traduzida no uso quotidiano. Ou seja, nos deparamos com os novos artefatos e passamos a interagir com eles e a incorporá-los em nossa cultura, sem termos contribuído para a sua formulação e existência. A isso corresponde uma visão determinista da C\&T.

Para enquadrar as diferenças entre determinismo, construcionismo, instrumentalismo e substantivismo, as maneiras de se entender e criticar a produção social das tecnologias, Feenberg (2009), em curso ministrado no Centro de Desenvolvimento Sustentável (CDS) em Brasília $^{3}$, apresentou um esquema (figura 5) no qual busca tornar claro o que diferencia tais posicionamentos.

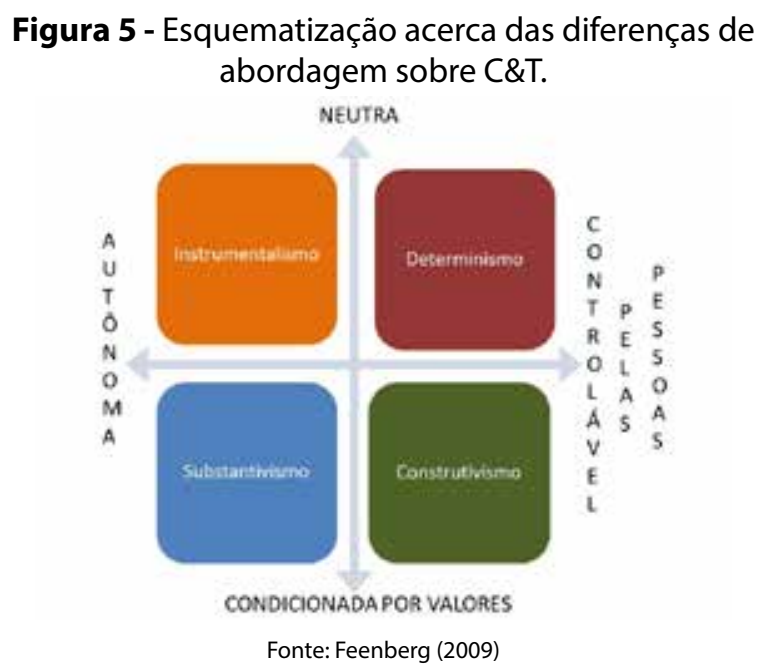

3 A Teoria Crítica da Tecnologia, de Andrew Feenberg: Racionalização Democrática, Poder e Tecnologia 
Esse autor considera que a sociedade precisa desenvolver uma capacidade crítica em relação à visão instrumental da C\&T. O instrumentalismo seria sinônimo de fazermos aquilo que quisermos, sem uma orientação adequada por valores. É um posicionamento apolítico e predomina entre os que consideram as atividades dos cientistas como algo norteado pela neutralidade e autonomia em relação às demandas, problemas e valores da sociedade. Feenberg exemplifica o posicionamento instrumentalista com a frase da Associação Nacional de Rifles dos EUA: "As armas não matam as pessoas, são as pessoas que matam as pessoas".

A compreensão do substantivismo, visão que considera a tecnologia como processo autônomo e guiado por valores, é mais bem compreendida em relação a dois conceitos da filosofia sobre a ciência e tecnologia, propostos por Idhe (1979). O autor trabalha com as ideias de "transparência” (transparency) e "incorporação ou amálgama" (embodiment), ao se referir à interação homem-máquina. Em virtude de estarmos acostumados com os artefatos, ou por não termos nenhuma participação de idealizadores ou construtores em sua realização, estes se tornariam transparentes, amalgamados, invisíveis ou opacos (FRITZGERALD-MOORE, 2005) no nosso dia a dia. Somente quando há um defeito ou questionamento sobre o artefato, a tecnologia migra para a esfera do visível, da reflexão, e ingressamos em um processo de desconstrução, de redução ou de análise de como a coisa surgiu. Para compreender isso, Feengerg simplifica ao enunciar que é como se estivéssemos "dentro da máquina”, e acrescenta: “a ferramenta que usamos nos molda”.

$\mathrm{O}$ pensamento crítico em relação à agenda de C\&T foi incentivado nas atividades de extensão universitária, iniciadas nos anos 1950 e 1960 . Tais iniciativas evoluíram e ganharam novas tonalidades na década de 1980, aproximando-se de um ideário que Hess (1997) chama de Estudos de Ciência, Tecnologia e Sociedade, ou somente CT\&S. No Brasil, o $\mathrm{S}$ de sociedade traz à baila a preocupação com assuntos referentes à justiça social, além de crescente multi e interdisciplinaridade nos processos comunicacionais de "unidades que iam além de organizações formais, como laboratórios, disciplinas, departamentos e organizações de pesquisa" (HESS, 1997, p. 73). Busca-se maior proximidade entre o problema de pesquisa e o problema social. A expressão invisible college, atribuída a Robert Boyle, no século XVII, mantém-se em processo de semiose e foi ressignificada em 1972, quando
Diana Crane a utilizou com o sentido de "redes de comunicação", "círculo social", "grupo de solidariedade”, no contexto da CT\&S.

\section{Semiose da palavra "tecnologia" e a opção pela tecnologia social}

Embora as tecnologias sociais possam ser entendidas com muitas diferenças de sentido (Figura 6) por todos que se dedicam a debatê-las (SENA, 2010), o ponto de consenso é de que sejam tecnologias construídas ou selecionadas de forma participativa por meio da ação comunicativa e capazes de promover melhor qualidade de vida. Para tanto, é preciso que as redes de comunicação, círculos sociais ou grupos de solidariedade, dentro e fora da Academia, constituam um processo comunicativo, denominado desenvolvimento local participativo (DLP). A prática do DLP tem como objetivo evitar processos decisórios que se resumam ao business as usual, como ocorre em casos de encomenda de um projeto de estrutura de parada de ônibus feita exclusivamente por não usuários de ônibus ou com descrição de requisitos que privilegiem interesses comerciais ou de licitações públicas, em detrimento das necessidades dos usuários.

Figura 6 - Conceitos de tecnologia social, diagramados de forma a ressaltar os elementos que os constituem

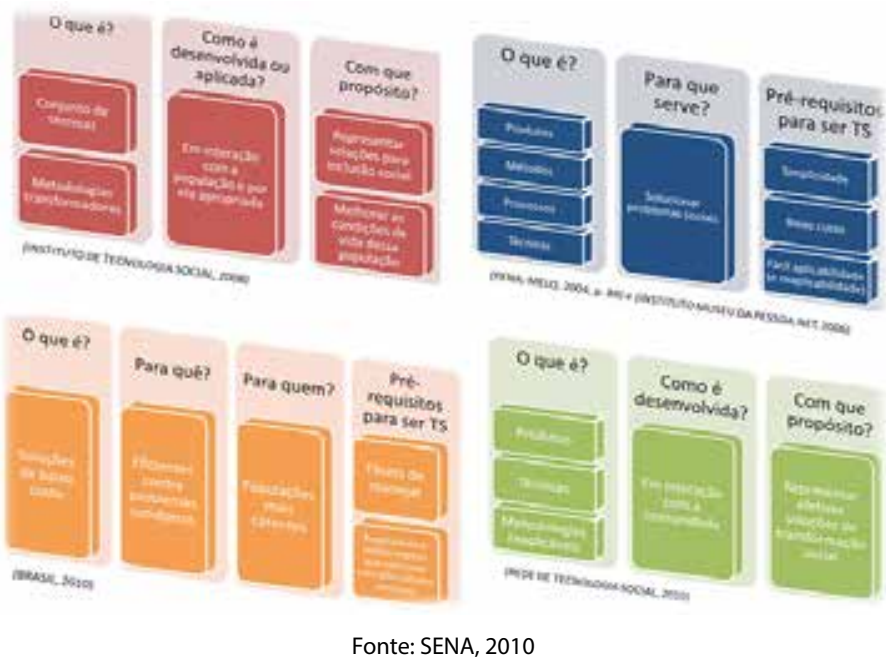

Desenvolvimento local participativo (INSTITUTO DE TECNOLOGIA SOCIAL, 2008) é uma atividade de construção de sentido ou de interrogação sobre sentidos. Para o exemplo dos abrigos, caso fosse realizada uma interação com o grupo com tal propósito, poderíamos aventar um questionamento do tipo: essa parada de ôni- 
bus atende às suas necessidades para a ação de espera em local público ou de acessibilidade ao transporte coletivo?

Figura 7 - Diversas adjetivações usadas para tecnologia, palavra em semiose, com proliferação de sentidos atrelados a valores

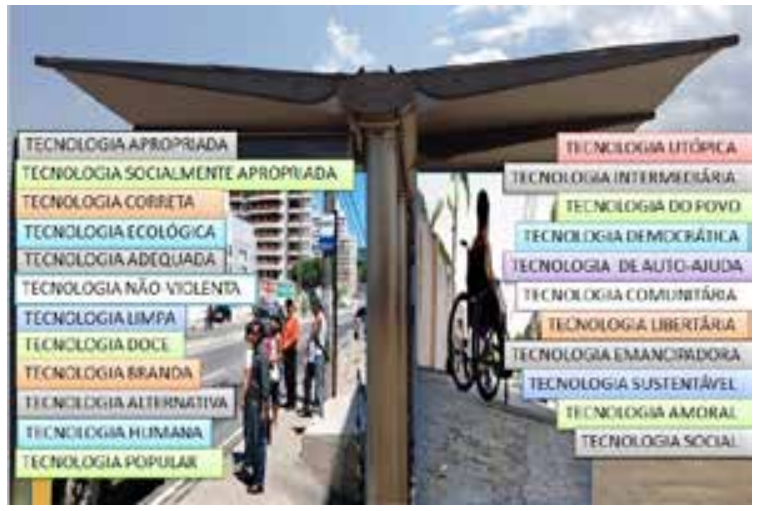

Fonte: Elaboração própria.

Um questionamento dessa natureza, se atende ou não às necessidades dos usuários, caso realizado em uma localidade em que o ponto de ônibus se limita a um ferro cravado no chão ou a uma parada de grife, incentivaria a reflexão e a participação comunitária em relação à engenharia do seu sistema de transporte coletivo. As perguntas e a interação dos usuários tirariam esse marco, enunciado como ponto de ônibus, retirado de sua inexistência aparente ou de seu "desaparecimento" na paisagem, o estado "invisível" da tecnologia, mencionada por Ihde (1979). Um alvoroço semelhante ocorreu quando novas paradas de ônibus foram lançadas em Curitiba, com design arrojado, no formato de tubo, que acabou virando cartão-postal da cidade:

A inauguração da primeira estação-tubo, em 1989, causou algum tumulto em frente à sede da prefeitura, na Cândido de Abreu, ali no Centro Cívico. A estrutura estava coberta e ninguém sabia ao certo como funcionaria. Muita gente aguardava pelo primeiro teste da parada com os modernos ligeirinhos. A plataforma do veículo deveria se encaixar perfeitamente à estrutura do ponto de ônibus, mas nem todos sabiam disso. Houve até quem imaginasse que seria o tubo a sair andando por aí. (CRUZ, 2015, p. 1 )

A semiose (todo signo interpreta outro signo) ou proliferação de adjetivos suscitados para a palavra tecnologia foi resgatada no trabalho de Brandão (2001), que estudou a história das tecnologias apropriadas. Selecionamos e dispusemos, na fotomontagem correspondente à figura 7 , alguns dos atributos justapostos à palavra tecnologia: correta, branda, utópica, não violenta, alternativa, humana, de autoajuda, libertária, comunitária, do povo, emancipadora, amoral, sustentável, social. Todas as palavras denotam uma busca por valores, por uma tecnologia controlável pelas pessoas e orientada para a promoção de qualidade de vida, logo, trata-se de uma abordagem construcionista.

Is small beautiful? A resposta à questão não é afirmativa para os que circulam nos carros de maior porte, equipados com as últimas inovações. Os motoristas parecem tão satisfeitos com a reconfiguração de poder que lhes é conferida pela tecnologia adquirida que podem esquecer-se de frear ao passar por uma pista alagada e acabar dando um banho nas pessoas que se encolhem nos pontos de ônibus em dias de temporal, cenas comuns no quotidiano brasiliense e que ilustram o "moldar-se à ferramenta", da observação de Feenberg. O livro de Schumacher (1973), Small is beautiful, aborda a questão da tecnologia intermediária, que não seria de baixo nível, no quesito da sua durabilidade, mas se manteria em um patamar do que mais tarde passou a ser considerado sustentabilidade, uma tecnologia com "face humana".

Renato Dagnino, em 1978, dedicou-se ao estudo das tecnologias apropriadas por ocasião de sua dissertação de mestrado. Manteve-se, desde então, partícipe dos debates, em interlocução com o que se tornou uma rede de tecnologia social, com diversas adesões individuais e institucionais, voltadas à tecnologia para a inclusão social. Ele diferencia tecnologias sociais (TSs) de tecnologias capitalistas ou convencionais (TCs). Tal polarização ganha filigranas em seus contornos ideológicos. $\mathrm{Na}$ abordagem dicotômica, a difusão de TSs é vista como um movimento político, contra-hegemônico. TSs teriam uma identidade diferenciada, em oposição às TCs, pois apresentariam a possibilidade de participação das comunidades. Em alguns países, há, inclusive, um discurso de coesão ou de identidade regional, um bloco latino-americano envolvido nesse movimento, como é o caso do Brasil, do México, da Argentina e do Uruguai (THOMAS; FRESSOLI, 2009). Esses autores mencionam o propósito de desenvolver uma metodologia de estudos de casos relacionados às tecnologias sociais no Brasil, no Uruguai e na Argentina. O México, também, tem parceiros em interlocução com a Rede de Tecnologias Sociais (RTS) ${ }^{4}$, como é o caso de

4 Sempre que houver referência à Rede de Tecnologia Social (RTS), <http://rts.ibict.br/>., instituição, usam-se maiúsculas. Ao haver referência à rede de tecnologia social, com minúsculas, trata-se de grupos ou redes de indivíduos sem filiação institucional à RTS e que se interessam por essa temática. 
Andrés Randazzo, da Ashoka ${ }^{5}$, organização da sociedade civil que trabalha com empreendedorismo social e tem projetos em diversas áreas relacionadas à erradicação da pobreza extrema.

Nos países desenvolvidos, existe a polinização do ideário das TSs, com outras características, em que se pretende promover uma nova revolução industrial. Em algumas situações se faz menção a folk technologies como alternativa para a tecnologia feita para o consumo de massa pelas grandes corporações. Nesse caso, o elemento da sofisticação, o objetivo do lucro, ou a característica high tech do produto não é rechaçado, pois é inerente à cultura dessas nações. O posicionamento é de empoderamento (empowerment) de qualquer pessoa que queira criar e produzir uma alternativa customizada de tecnologia, independente de qualquer cadeia produtiva estabelecida. Nesse contexto, em vez de encomendar produtos à indústria, são as pessoas que irão criá-los, no estilo hands on, o nosso "colocar a mão na massa". Se fosse uma parada de ônibus a razão da insatisfação, por exemplo, outro modelo seria concebido, construído, proposto e testado como protótipo.

Um exemplo notório é o da AS2207, grupo de artistas de uma ONG de Providence, capital do menor estado americano, Rhode Island. Em 2008, a ONG pegou empréstimo de US $\$ 1,6$ milhão com a Prefeitura, em projeto orçado em US\$12 milhões, para ampliar o espaço do laboratório que pertence à comunidade. O grupo trabalha com tecnologia de design e fabricação. O parceiro na empreitada é o Massachusetts Institute of Technology (MIT), de quem a ONG comprou as tecnologias de design e fabricação para permitir o acesso a qualquer um que queira experimentar os softwares e hardwares de robustez industrial: "para sair de uma ideia, gerar um modelo no computador e construir rapidamente um protótipo".

A ideia original é do $\mathrm{Fab} \mathrm{Lab}^{8}$ do Center for Bits and Atoms (CBA) do MIT, que busca fazer com que o cidadão leigo (ordinary people) não só aprenda sobre ciência e engenharia, mas também seja capaz de desenhar máquinas e fazer mensurações relevantes para melhorar

Para saber mais: <http://mexico.ashoka.org/>.

6 A tese da estratégia do colibri (MORACE, 2008) ou "polinização criativa" entre culturas.

Para saber mais acesse: <http://as220.org/front/>.

8 Fab(rication) Lab(oratories) <http://fab.cba.mit.edu/>. Para conhecer o tipo de hardware e software que estão sendo usados, visite: <http://fab.cba.mit.edu/content/tools/>. a própria qualidade de vida. Surgiu de uma disciplina intitulada How to make (almost) anything [como fazer (quase) qualquer coisa]. Outros projetos em desenvolvimento pelo Fab Lab incluem turbinas que geram energia solar e eólica, computadores para rede sem disco duro, instrumentação analítica para a agricultura e saúde, para citar alguns. A perspectiva é a de inverter o processo de invenção e inovação e possibilitar, a quem tiver interesse, que este seja feito de baixo pra cima (bottom up $)^{9}$.

O Instituto de Tecnologia Social (ITS) desenvolveu metodologia para aferir se uma tecnologia pode ser considerada social em observância ao significado que atribui-se ao termo: "conjunto de técnicas e metodologias transformadoras, desenvolvidos em interação com a população, e por ela apropriadas, que representem soluções para a inclusão social e melhoria das condições de vida dessas populações". (INSTITUTO DE TECNOLOGIA SOCIAL, 2007, p. 29). A instituição é pioneira na organização de fóruns de debate, com ampla variedade de atores, nos quais se questiona o papel da C\&T para o desenvolvimento com qualidade de vida. O instituto especificou quatro dimensões a serem consideradas na aplicação dessa metodologia: "a dimensão do conhecimento, ciência, tecnologia e inovação; a dimensão da participação, cidadania, democracia; a dimensão da educação; a dimensão da relevância social” (GARCIA, 2007).

\section{Considerações Finais}

Neste artigo, inclui-se o exemplo de uma parada de ônibus para analisar alguns aspectos associados à incessante busca de adjetivação do fazer tecnológico da nossa espécie. Se cada um de nós escrevesse um diário com a inclusão de todos os artefatos com os quais tem interação, do amanhecer ao anoitecer, do mais simples ao mais complexo, seria possível compilar um catálogo individualizado do universo tecnológico de cada pessoa, tirando-a de seu estado de transparência. Ao jogar luz nesse mundo inanimado que nos cerca - espécie de floresta de símbolos de Baudelaire -, haveria a chance de separar e investigar, uma a uma, as peças do quebra-cabeça tecnológico individual, com as razões por que tais partes foram selecionadas e obtidas, que funcionalidades existem,

9 Para saber mais acesse: <http://www.garagemfablab.com/rede-fab-lab/>. 
com que grau de indispensabilidade ou superficialidade para a vida que se leva, bem como os cenários construídos por nós mesmos ou nos quais somos jogados, sem a possibilidade de interferir no cenário, figurino e papéis desempenhados.

Em relação ao questionamento introdutório: Como uma tecnologia pode não ser social, se todas surgem em meio à sociedade? Exibiram-se as limitações do design dos abrigos de ônibus e fez-se desse fato um meio de ingresso no ideário do movimento $\mathrm{C}, \mathrm{T} \& \mathrm{~S}$ que envolve a discussão sobre como incluir um problema social como problema de pesquisa ou até como item de currículo escolar, promotor do DLP. A Arquitetura e o Urbanismo pertencem à área das Ciências Sociais Aplicadas e estão sempre em interação com o desafio de desenhar e projetar estruturas para as pessoas, em diferentes contextos. $\mathrm{O}$ descaso e a massificação ou produção em série de unidades de abrigos de ônibus prejudicam iniciativas construcionistas, mas há iniciativas que puderam ser localizadas como contracultura, seja na estética diferenciada, personalizada, com um Cristo colocado no teto, em novos usos inusitados para as paradas, ou até concepções inovadoras, como os dos abrigos de Curitiba. Ao fazer o que querem, $\mathrm{o}$ arquiteto, o administrador, o gestor e os usuários interagem com um universo instrumental ou determinista de fazer ciência e tecnologia.

A tecnologia social não foi apresentada neste artigo como um modelo a ser reproduzido, ideal ou dogma. Incluiu-se a noção de semiose - um sentido que gera outro sentido, ou a capacidade diferenciada de atribuições de sentido - com o intuito de percorrer um caminho já trilhado por outras mentes, com o enunciado de como varia uma visão construcionista, substantivista, determinista ou instrumentalista da ciência e tecnologia. Se a afirmação da Associação Nacional de Rifles dos EUA pareceu puro bom senso ou se causou aversão, isso é o início de uma reflexão sobre suas convicções, em consonância ou dissonância de sentido em relação ao universo das tecnologias sociais. Os leitores deste artigo poderão refletir a respeito desse tema e das questões propostas, se já tiveram a experiência com transporte coletivo.

Em relação ao movimento de C,T\&S, o "S" da sociedade entra em cena quando há intenções de realizar um inventário dos problemas locais, com propostas de soluções. Nesse contexto, cogitam-se mensurações dos índices de desenvolvimento humano, aferições nem sempre plausíveis de serem conduzidas. No universo subje- tivo de mensuração de qualidade de vida, as tecnologias feitas sob a ótica do benefício individual e social têm papel destacado, e foi esse o intuito dessa reflexão. No quantitativo e no qualitativo das TSs, entram saúde, educação, atividades pessoais, participação política e governança, conexões sociais, condições ambientais, segurança, insegurança econômica, desigualdades. Assim, a irrelevância de um abrigo de ônibus conquista novo olhar. Este artigo é um aceno, como o que se faz para o motorista de ônibus que tem o poder de encerrar (ou não) o tempo da espera.

\section{Referências}

ARAÚJO, Roberto Gonçalves de. Cinquenta anos do mobiliário do transporte público de Brasília. 2010. $263 \mathrm{f}$. Dissertação (Mestrado) - Curso de Arquitetura e Urbanismo, Faculdade de Arquitetura e Urbanismo, Universidade de Brasília, Brasília, 2010. Disponível em: <http:// bit.ly/1UXeRoB $>$. Acesso em: 3 set. 2015.

BAITELLO JUNIOR, Norval. O animal que parou os relógios. São Paulo: Annablume, 1997.

BIJKER, Wiebe; PINCH, Trevor. The social construction of facts and artifacts: or how the sociology of science and the sociology of technology might benefit each other. Disponível em: <http://bit.ly/1UXdBSc $>$. Acesso em: 17 set. 2015.

BRANDÃO, Flávio Cruvinel. Programa de apoio às tecnologias apropriadas (PTA): avaliação de um programa de desenvolvimento tecnológico induzido pelo CNPq. 2001. 191 f. Dissertação (Mestrado) - Curso de Política e Gestão de Ciência e Tecnologia, Departamento de Centro de Desenvolvimento Sustentável, Universidade de Brasília, Brasília, 2001. Disponível em: <http://bit.ly/1NFQkW1>. Acesso em: 17 set. 2015.

BRASIL. Secretaria de Comunicação Social da Presidência da República. Portal Brasil - Revista digital: Rede de Tecnologia Social. Disponível em: <http://revista.brasil. gov.br/Especiais/Rede-de-Tecnologia-Social-10.aspx $>$. Acesso em: 24 set. 2010.

CAITANO, Adriana. IPEA: 70\% da população está insatisfeita com transporte. 2011. Disponível em: <http://abr. ai/1W4UZlO>. Acesso em: 06 set. 2015.

CRUZ, Eloá. A evolução dos pontos de ônibus em Curitiba. Haus - Gazeta do Povo. Curitiba, 2015. Disponível em: <http://bit.ly/1YfWJuq >. Acesso em: 17 set. 2015.

DAGNINO, Renato (Org.). Tecnologia social: ferramenta para construir outra sociedade. Instituto de Geociências da Unicamp, 2009. Disponível em: <http://www.ige.unicamp.br/gapi/old/GAPI\%20Tecnologia\%20Social\%20 
ferramenta $\% 20$ para $\% 20$ construir $\% 20$ outra $\% 20$ sociedade.pdf>. Acesso em: 06 set. 2015.

EMPRESA BRASILEIRA DE COMUNICAÇÃO. Brasil é campeão mundial em incidência de raios: saiba como se proteger. 2014. Disponível em: <http://www.ebc.com. $\mathrm{br} /$ noticias/meio-ambiente/2014/12/brasil-e-campeao-mundial-em-incidencia-de-raios-saiba-como-se $>$. Acesso em: 06 set. 2015.

ECO, Humberto. Lector in fabula. 2. ed. São Paulo: Perspectiva, 2004.

FEENBERG, Andrew. Racionalização subversiva: tecnologia, poder e democracia. In: NEDER, Ricardo. A teoria crítica de Andrew Feenberg: racionalização democrática, poder e tecnologia. Brasília: CDS/UnB/Capes, 2010. p. 6995. Disponível em: <http://pt.scribd.com/doc/61221945/ Filosofia-Da-Tecnologia-Andrew-Feenberg\#scribd $>$. Acesso em: 06 set. 2015.

FRITZGERALD-MOORE, Peter. Technological Change Part III: the trajectory of technological devices and systems. The Universal Amplifier: Lectures on Technology and Society. Calgary, 2005. Disponível em: <http://people.ucalgary.ca/ pfitzger/traject.pdf $>$. Acesso em: 06 set. 2015.

FRUTIGER, Adrian. Sinais e símbolos: desenho, projeto e significado. São Paulo: M. Fontes, 1999.

GARCIA, Jesus Carlos Delgado. Uma metodologia de análise das tecnologias sociais. In: SEMINARIO LATINO-IBEROAMERICANO DE GESTIÓN TECNOLÓGICA, 12, 2007. Disponível em: <http://bit.ly/1izf85k>. Acesso em: 06 set. 2015.

HESS, David J. Science studies: an advanced introduction. New York: New York University Press, 1997.

IHDE, Don. Technics and praxis: a philosophy of technology. Springer Science \& Business Media, 1979. Disponível em: <http://bit.ly/1Jdm8JZ>. Acesso em: 06 set. 2015.

INSTITUTO DE TECNOLOGIA SOCIAL (ITS). Caderno Tecnologia Social: conhecimento e cidadania 1. São Paulo: ITS, 2007. Disponível em: <http://bit.ly/1iRLhFb $>$. Acesso em: 17 set. 2015.

INSTITUTO DE TECNOLOGIA SOCIAL (ITS). Desenvolvimento Local Participativo no Distrito Federal: em São Sebastião, Itapoã e Mestre D'Armas as comunidades constroem seu própio futuro. Revista Conhecimento: ponte para a vida, São Paulo, v. 2, n. 6, p. 1-10, out. 2008.

INSTITUTO MUSEU DA PESSOA.NET (Ed.). Tecnologia social da memória: guia para comunidades, organizações sociais e instituições organizarem sua memória. São Paulo: Nacional/Ibep, 2006. Disponível em: <http://www.fbb.org.br/upload/biblioteca/documentos/1211376560375.pdf $>$. Acesso em: 16 set. 2010.

KIRKPATRICK, Graeme. Technology and social power. Hampshire, Inglaterra: Palgrave Macmillan, 2008.

MORACE, F. A globalização e o futuro brasileiro. In: GLOBALIZAÇÃO da economia têxtil e de confecção brasileiro: empresários, governo e academia unidos pelo futuro do setor. Rio de Janeiro: Cetiqt/IPTM, 2007. p. 329.

PAZ, Daniel J. O cidadão ausente: a cidade de Salvador e os seus abrigos de ônibus. Arquitextos. Portal Vitruvius, 2004. Disponível em: <http://bit.ly/1YfXSCp>. Acesso em: 17 set. 2015 .

PENA, Jacques de Oliveira; MELLO, Claiton José. Tecnologia social: a experiência da Fundação Banco do Brasil na disseminação e reaplicação de soluções sociais efetivas. In: REDE DE TECNOLOGIA SOCIAL. Tecnologia social: uma estratégia para o desenvolvimento. Rio de Janeiro: Fundação Banco do Brasil, 2004. p. 83-87.

PROPMARK. Cemusa fecha contrato de US\$ 1 bilhão com Prefeitura de Nova York. 2005. Disponível em: <http://bit. ly/1KoH8hK>. Acesso em: 06 set. 2015.

REDE DE TECNOLOGIA SOCIAL (Org.). Tecnologia social e desenvolvimento sustentável: contribuições da RTS para a formulação de uma política de estado de ciência, tecnologia e inovação. Brasília: Secretaria Executiva da Rede de Tecnologia Social (RTS), 2010.

ROLNIK, Raquel. Pontos de ônibus: por que é tão difícil garantir qualidade e conforto? 2013. Disponível em: $<$ https://raquelrolnik.wordpress.com/2013/03/18/pontos-de-onibus-por-que-e-tao-dificil-garantir-qualidade-e-conforto/>. Acesso em: 06 set. 2015.

SCHROEDER, Ralph. Rethinking Science, Technology and Social Change. Stanford: Stanford University Press, 2007.

SCHUMACHER, E. F. Small is beautiful: a study of economics as if people mattered. New York: Harper \& Row, 1973. Disponível em: <http://bit.ly/1LAm1tO>. Acesso em: 17 set. 2015 .

SENA, Nathália Kneipp. Tecnologias sociais: processos comunicativos em autopoiese. 2010. 199 f. Dissertação (Mestrado) - Universidade Católica de Brasília, Brasília, 2010. Disponível em: <http://bit.ly/1W4W2Ch>. Acesso em: 17 set. 2015 .

THOMAS, Hernán; FRESSOLI, Mariano. En búsqueda de una metodología para investigar tecnologías sociales. In: DAGNINO, Renato (Org.). Tecnologia social: ferramenta para construir outra sociedade. Campinas: IG/Unicamp, 2009. Disponível em:<http://bit.ly/1MehrnW>. Acesso em: 5 jun. 2009. 